\title{
Anterior Annulus of the Mitral Valve
}

National Cancer Institute

\section{Source}

National Cancer Institute. Anterior Annulus of the Mitral Valve. NCI Thesaurus. Code C127668.

The portion of the mitral valve annulus that attaches to the anterior mitral valve leaflet, and also forms the mitral portion of the aortic-mitral curtain. 